\title{
Proposta para Avaliação da Gestão do Conhecimento em Entidade Filantrópica: o Caso de uma Organização Hospitalar
}

\author{
Romualdo Douglas Colauto \\ Ilse Maria Beuren
}

\begin{abstract}
Resumo
O atual ambiente organizacional intensifica a importância em adquirir e gerenciar o conhecimento humano e o aprendizado interativo contínuo. O crescimento da valorização do conhecimento pode ser considerado inevitável, uma vez que o fluxo de investimentos em pessoas e a utilização plena da inteligência dos participantes da empresa dissemina-se pelo mundo e converge para uma economia baseada no conhecimento. Assim o gerenciamento do conhecimento deve fazer parte das estratégias das organizações. Nessa perspectiva, o trabalho tem por objetivo apresentar uma proposta de metodologia de avaliação da gestão do conhecimento para uma organização hospitalar, caracterizada como entidade filantrópica. Propõe-se que a alta administração faça a ligação das informações dos indicadores com o planejamento e a tomada de decisões estratégicas. Busca-se, inicialmente, evidenciar os aspectos caracterizadores das entidades filantrópicas, os conceitos e as metodologias de avaliação da gestão do conhecimento. A partir disso, sugere-se uma metodologia de avaliação para o segmento. Na seqüência, apresenta-se sua aplicação em uma entidade. Acredita-se que o trabalho possa servir de sugestão, para que outras organizações elaborarem seu próprio modelo de avaliação da gestão do conhecimento.
\end{abstract}

Palavras-chaves: gestão do conhecimento; avaliação; organização hospitalar.

\begin{abstract}
The current organizational environment increases the importance of acquiring and managing human knowledge and of on-going interactive learning. The growth in the value of knowledge may be considered inevitable, once the flow of investment in people and the total use of intelligence by the members of an enterprise spread around the world and converge to an economy based on knowledge. Thus, the management of knowledge should be part of the strategies of companies. Having this in mind, this paper aims at presenting a methodology proposal for the evaluation of knowledge management for a hospital characterized as philanthropic. It proposes that the board should make the link between information and planning and strategic decision making. The first step is to attempt to disclose not only the aspects that characterize a philanthropic entity as such, but also concepts and methodologies for the evaluation of knowledge management. Then, a methodology of evaluation is suggested. After that, the application of the methodology is presented. It is our belief that this may work as a suggestion for other organizations to build their own evaluation models for the management of knowledge.
\end{abstract}

Key words: knowledge management; evaluation; companies hospital. 


\section{Considerações Preliminares}

Vive-se num mundo de mudanças políticas, econômicas e sociais que afetam as organizações e as pessoas. Logo a intensificação da necessidade de adquirir e gerenciar o conhecimento humano e a aprendizagem interativa contínua é premente para se adquirir e manter um diferencial competitivo na era da informação. As mudanças ressaltam a crescente importância que as organizações assumem para a sociedade contemporânea e, por conseguinte, para os homens que a constituem.

Assumindo este posicionamento, Gonçalves (1987) considera as organizações como unidades sociais ou comunidades humanas intencionalmente construídas para atingir objetivos específicos. A justificativa maior para a existência das organizações está relacionada à concretização das metas ambicionadas pelos homens, as quais somente são alcançadas mediante a atuação convergente de certo número de participantes. Assim, na medida em que os indivíduos exigem o oferecimento de novos bens e serviços para sobrevivência, confirma-se a premissa de que uma pessoa não pode atingir suas metas individualmente.

No contexto em que as necessidades dos homens são ilimitadas, os recursos para satisfazê-las escassos e frente limites da capacidade humana, torna-se impossível viver em completo isolamento, sendo este um dos fatores que impulsionou o surgimento das sociedades. A reunião dos homens em sociedade proporcionou a divisão do trabalho, a colaboração mútua e a especialização em determinadas atividades. Por meio da contingência da vida em sociedade surgem as organizações que nela atuam.

Não obstante, acredita-se que as organizações não sejam apenas instrumentos de produção de bens e serviços, mas o ambiente no qual os homens contemporâneos estão inseridos para passar toda a sua vida, representando o cenário no qual se desvenda o seu destino, e que permite ou nega a possibilidade de realizarem plenamente as suas ambições. Por conseguinte, as organizações caracterizam-se como elementos relevantes para o desenvolvimento socioeconômico de uma nação, ao proporcionarem a realização dos objetivos da coletividade. Ter um propósito definido para as organizações, centraliza a atenção no que é relevante e desenvolve as suas habilidades para atingir seus objetivos.

Nesse conceito de organização enquadram-se as organizações do primeiro, segundo e terceiro setor. Jeremias e Beuren (2000) citando Fernandes (1994) mencionam que o primeiro setor é composto pelo Estado (público), o segundo 
pelo mercado (privado) e o terceiro setor não é público e nem privado, mas um conjunto de organizações e iniciativas privadas que visam a produção de bens e serviços públicos. Neste último, enquadram-se as organizações prestadoras de serviços, sejam elas com ou sem fins lucrativos.

Falconer (2000) advoga que o terceiro setor, ou das organizações sem fins lucrativos, é, atualmente, um dos temas que mais desperta interesse no meio acadêmico brasileiro. Este interesse é reflexo de um conjunto de tendências complexas e inter-relacionadas, como: (1) adoção do discurso da cidadania empresarial e da responsabilidade social por parte de empresas privadas; (2) programas de reforma do Estado que ocorrem no âmbito do governo federal, estadual e municipal, alicerçados nos pilares de descentralização política e administrativa; e (3) movimento de progressiva democratização da sociedade brasileira que, aos poucos, deixa para trás a herança do período autoritário.

As organizações precisam viabilizar o desenvolvimento de habilidades das pessoas que as integram, com vistas a alcançarem os objetivos estabelecidos; esse propósito, conseqüentemente emerge a necessidade da gestão do conhecimento. Nessa perspectiva, o objetivo deste trabalho é apresentar uma proposta de metodologia de avaliação da gestão do conhecimento para uma organização hospitalar, caracterizada como entidade filantrópica.

Ressalta-se que estudos sobre a avaliação da gestão do conhecimento com uso de indicadores não financeiros, ainda são incipientes no Brasil. Uma abordagem verossímil é achada em Zucchi (1998), que propõe estudar o dimensionamento da força do trabalho humano de seis hospitais de São Paulo. Marinho (2001) comenta que os indicadores de desempenho de recursos humanos desses hospitais podem e devem ser ampliados com recursos analíticos já disponíveis e utilizados em larga escala no exterior, mas incipientes no Brasil.

Entende-se que a proposta para avaliação da gestão do conhecimento em uma organização hospitalar filantrópica, contempla aspectos importantes para corroborar as pesquisas que buscam materializar os aspectos conceituais da gestão do conhecimento, por meio de medidas de desempenho e de eficiência capazes de estabelecer referências virtuosas ao processo de gestão.

\section{Procedimentos Metodológicos}

O delineamento da pesquisa caracterizou-se como estudo exploratório, com uso de fontes secundárias, com abordagem lógica dedutiva. Quanto 
aos procedimentos sistemáticos para a descrição e explicação dos fenômenos, o estudo se desenvolveu num ambiente que preconizou a abordagem qualitativa.

Utilizou-se a pesquisa bibliográfica para a formação do marco referencial teórico e do estudo de caso centrado em uma única organização. A escolha do sujeito da pesquisa foi intencional em função da acessibilidade aos dados necessários, haja visto o exercício profissional de um dos autores. Como instrumentos de pesquisa, efetuou-se exame dos registros existentes na organização e entrevistas não-estruturadas com o Diretor Administrativo da entidade. Utilizou-se também o conhecimento e a experiência acumulada de um dos autores no exercício da sua atividade profissional nessa instituição durante vários anos, como forma de auxiliar a aprofundar o conhecimento sobre o problema de estudo.

Quanto à organização do conteúdo, inicialmente fez-se uma incursão teórica nos aspectos caracterizadores das entidades filantrópicas e das organizações hospitalares, dado suas particularidades em termos de não objetivar lucros e tratar da vida dos seres humanos, respectivamente. Na seqüência, abordou-se a gestão do conhecimento, o conhecimento na organização e algumas metodologias de avaliação da gestão do conhecimento. A seguir, contemplou-se a proposta de metodologia de avaliação da gestão do conhecimento para uma entidade filantrópica voltada à área de saúde. Por fim, mostrou-se a aplicação da proposta em uma organização hospitalar filantrópica.

\section{Entidades Filantrópicas}

Em face das mudanças econômicas que afetam o país, dos esforços para a democratização das atividades e do aumento das carências sociais, o Governo tem procurado encorajar o desenvolvimento de organizações não-governamentais, sem finalidades lucrativas, para desempenharem atividades voltadas ao interesse público e social em parceria com ele. Conseqüentemente, estas organizações do terceiro setor tornam-se, ao longo do tempo, importantes agentes para a melhoria da sociedade, da democracia, da estabilidade social, do fortalecimento e desenvolvimento econômico na adequação do mercado.

As instituições sem finalidades lucrativas merecem lugar de destaque na atividade socioeconômica do Brasil. Segundo Akselrad (2000), estas instituições, embora pessoas jurídicas de direito privado, colaboram de maneira direta e efetiva com os poderes públicos, assumindo inúmeras tarefas, principalmente voltadas 
às áreas de assistência social, saúde e educação, em parceria ou, até mesmo, em substituição ao Estado. Por tais razões, no Brasil, tradicionalmente, a Constituição Federal tem garantido imunidade tributária às organizações, instituições ou entidades sem finalidades lucrativas, que ocupam atividades relevantes nas áreas social ou econômica.

A Lei n. 9.790/99 ou Lei das Oscips institui que podem se qualificar como Organizações da Sociedade Civil de Interesse Público as pessoas jurídicas de direito privado, sem fins lucrativos, desde que os respectivos objetivos sociais e normas estatutárias atendam aos requisitos de não distribuir, entre os seus sócios ou associados, conselheiros, diretores, empregados ou doadores, eventuais excedentes operacionais, brutos ou líquidos, dividendos, bonificações, participações ou parcelas de seu patrimônio auferido mediante o exercício de suas atividades, e que os apliquem integralmente na consecução do objeto social da entidade.

Para caracterizar-se como uma entidade filantrópica beneficente de assistência social, de acordo com o Conselho Nacional de Assistência Social, ela deve atuar no sentido de: (1) proteger a família, a maternidade, a infância, a adolescência e a velhice; (2) amparar crianças e adolescentes carentes; (3) promover ações de prevenção, habilitação e reabilitação de pessoas portadoras de deficiências; (4) promover, gratuitamente, assistência educacional ou de saúde; (5) promover a integração ao mercado de trabalho; e (6) promover o atendimento e o assessoramento aos beneficiários da Lei Orgânica da Assistência Social e a defesa e garantia dos seus direitos.

Nota-se que as entidades filantrópicas exploram atividades de prestação de serviços, cuja obrigação consubstancia-se em oferecer atendimento às áreas de educação, ao adolescente, ao menor, ao idoso, reabilitação ao trabalho e à saúde, de tal sorte que seja absolutamente inconteste e sem finalidade lucrativa a vinculação com a assistência social da comunidade. Nesse sentido, a gestão dessas organizações exige determinada postura de seus lideres, a qual só pode ser alcançada a partir do real conhecimento das necessidades dos homens e da acirrada consciência da solidariedade social.

Respeitando os requisitos apresentados, as organizações hospitalares podem ser consideradas entidades filantrópicas. Como o foco de análise está centrado em uma organização com essa finalidade, na seqüência faz-se uma breve incursão acerca do objeto e objetivo dessas entidades que integram o campo da saúde, para maior clareza das proposições. 


\section{Objeto e Objetivo das Organizações Hospitalares}

As organizações hospitalares têm papel preponderante a cumprir na construção de um mundo novo, devendo, para tanto, também assumir responsabilidades sociais para com a comunidade. Segundo Campos (1986), as organizações modernas devem preocupar-se e responsabilizar-se pela qualidade de vida, atendendo aos valores básicos, crenças e objetivos fundamentais que norteiam a época e a sociedade na qual estão inseridas.

Não há como eximir o hospital da analogia a uma empresa. Este possui os mesmos problemas de receitas e despesas, ordem legal, administrativa, trabalhista, além da sistemática global do empresariado capitalista, ou seja, busca sobremaneira a maximização do superávit financeiro, indispensável para acompanhar a evolução tecnológica médica e ampliar ou manter seu capital estrutural.

De modo genérico, o objeto social da empresa hospitalar é fixado com base na idéia que os membros constitutivos têm sobre o ramo de especialização a ser explorado. Assim, ao se formar uma instituição filantrópica com a finalidade de atuar no campo hospitalar, é muito provável que o objeto social envolvido seja proveniente da necessidade que um grupo de pessoas observou como carência de uma comunidade. Portanto, a alusão é específica à prestação de serviços.

Com relação aos objetivos constitutivos das organizações hospitalares, compreendem a captação, administração e maximização dos recursos, a fim de oportunizar o contínuo atendimento médico. Reportando-se aos aspectos gerenciais dessas organizações enquadradas como entidades beneficentes, além de cuidar dos aspectos do ambiente interno, devem considerar os elementos estratégicos norteadores do atual ambiente econômico. Nesse sentido, assume relevância a sua gestão do conhecimento.

O sucesso da administração hospitalar reside no melhor aproveitamento racional dos recursos estruturais, humanos e de clientes, requerendo para tal intento, que cada estratégia operacional seja direcionada no sentido da consecução dos objetivos institucionais da organização. Marinho (2001), ao fazer referência a Mintzberg e Quinn (1996), coloca que os hospitais devem ser tratados como organizações profissionais. Para que essas organizações funcionem bem, tudo depende da capacitação e dos conhecimentos de seus executores. Ele explica que, por envolver aspectos subjetivos, os resultados das organizações profissionais não são facilmente medidos ou padronizados. As dificuldades de mensuração têm sido contornadas, parcialmente, para efeitos gerenciais, usando-se indicadores de desempenho. 


\section{Gestão do Conhecimento}

A intensificação do valor do conhecimento humano e da aprendizagem contínua é premente para as organizações adquirirem e manterem um diferencial competitivo na era da informação. Investir em pessoas e utilizar a inteligência plena dos participantes da empresa melhora a qualidade, eficiência, eficácia e amplia a competitividade.

Termos como a gestão do conhecimento, capital intelectual, inteligência competitiva são caracterizadores da nova área de interesse da administração das organizações. Emergem como uma conseqüência da globalização, evolução tecnológica e do desmantelamento da hierarquia empresarial da era industrial, buscando administrar a utilização, criação e disseminação do conhecimento, a partir da premissa de que este se tornou um recurso econômico proeminente de grande importância nas organizações.

A gestão do conhecimento, vista na perspectiva atual, surgiu na década de 1990, como uma proposta de agregar valor à informação e facilitar o fluxo interativo em toda corporação. Usada adequadamente, é tida como instrumento estratégico competitivo resistente ao modismo da eficiência operacional. Segundo Sveiby (2000), o tema centra-se em aproveitar recursos existentes na empresa, proporcionando a seus integrantes empregar as melhores práticas e poupar o reinvento de processos.

A gestão do conhecimento está, conforme Fleury e Fleury (2000), imbricada nos processos de aprendizagem nas organizações, conjugando três processos: (1) aquisição e desenvolvimento de conhecimentos; (2) disseminação; e (3) construção de memórias em um único processo coletivo de elaboração das competências necessárias à organização. Teixeira Filho (2000) explicita que é a coleção de processos que governam a criação, disseminação e utilização do conhecimento para atingir plenamente os objetivos. É uma nova confluência entre Tecnologia da Informação e Administração, um novo campo entre a estratégia, a cultura e os sistemas de informação da organização.

Pensar em gestão do conhecimento somente com foco no uso intenso da tecnologia é um conceito rudimentar, pois a tecnologia fornece estrutura, porém não fornece conteúdo. Para Sveiby (2000) trata-se de um assunto relacionado a pessoas. Certamente a tecnologia é um facilitador, mas por si só não consegue extrair informações da cabeça de um indivíduo. Nesse sentido, Kotler (1998) alerta que as empresas vêem a tecnologia como produtora de interminável fluxo de oportunidades. Todavia levar vantagem na tecnologia significa percorrer uma 
linha tênue. Portanto a presença do ser humano é fundamental à viabilidade e geração de valor nas empresas.

O interesse das organizações no conhecimento, segundo Teixeira Filho (2000), se deve, entre outros aspectos, ao fato do conhecimento estar associado à ação. O conhecimento é avaliado pelas decisões que desencadeia. Um melhor conhecimento pode levar a melhores decisões em marketing, vendas, produção e distribuição.

Com o enfoque da gestão do conhecimento, as empresas passaram a se preocupar com seu capital intelectual e com sua inteligência competitiva. De forma que se inicia um novo processo para rever a organização, suas estratégias, estruturas e, principalmente, a cultura organizacional. Analogamente, pode-se ver a gestão do conhecimento como um processo de Qualidade Total, em que as organizações se preocupam com o conhecimento tácito e sua explicitação durante todo o ciclo de negócios, uma vez que disseminar o conhecimento do corpo funcional, como será abordado na seqüência, é fato crucial na estratégia das organizações.

A gestão do conhecimento trata o capital intelectual como um recurso que deve ser administrado. Em hospitais, em particular, Bansal (2001) coloca que o cuidado com os pacientes é melhorado, em razão proporcional aos ativos intelectuais da organização. Logo deveria ser possível capturar as perícias táticas e experiências individuais dos trabalhadores para serem refletidas em estratégias, políticas e práticas em todos os níveis da administração do hospital e no atendimento aos clientes. Ele enfatiza que o recurso intangível, conhecimento dos profissionais, pode criar inovações radicais na gestão e na cultura organizacional.

Beulke e Bertó (2000), reportando-se às organizações hospitalares, comentam que o desenvolvimento de modelos gerenciais que possibilitem retorno adequado sob a ótica do resultado, associado ao grau de satisfação dos clientes, do ponto de vista do atendimento e a uma estrutura enxuta, constituem o alicerce para o sucesso dessas organizações. Eles relatam ser coerente que as instituições de saúde, como qualquer outro empreendimento, para apresentarem uma posição salutar com equilíbrio e atualização tecnológica, necessitem de resultados positivos.

Acredita-se que a gestão do conhecimento em instituições hospitalares, ao criar um espectro sinérgico de compartilhamento do conhecimento, efetivamente beneficia a redução do tempo de ciclo dos serviços, diminui os custos, gera mais retorno dos investimentos, melhora a satisfação dos pacientes e incentiva o 
aprendizado contínuo dos médicos, paramédicos e outros profissionais para a prestação de serviços com mais excelência.

\section{O Conhecimento na Organização}

Com a ênfase na valorização do conhecimento e na aprendizagem, intensificase a emergência dos trabalhadores e das empresas em desenvolverem competências para promover e aprimorar suas habilidades, dada a turbulência competitiva que converge a desafios simultâneos e diversificados. Stewart (1998, p.8) entende que "o conhecimento é mais valioso e poderoso do que os recursos naturais, grandes indústrias ou polpudas contas bancárias".

Para ampliar ou manter a competitividade e qualidade, faz-se necessário, tanto no âmbito interno como externo, que as organizações usem a inteligência e o conhecimento do corpo funcional. Para isso necessitam investir em pessoas nelas inseridas, o que pode gerar dispêndios superiores aos investimentos realizados em ativos tangíveis. Esse novo foco de investimento é apresentado por Flamholtz (apud Pacheco, 2001, p. 35), ao comentar:

"a característica distintiva da economia emergente é a ênfase crescente no capital humano - o conhecimento, especialização e experiências das pessoas em vez de no capital físico. Um dado evidenciado é o custo de se desenvolver o capital humano; investimentos significativos exigidos pelos indivíduos e as organizações que os empregam”.

A gestão do conhecimento nas organizações se viabiliza com base em informações. Nonaka e Takeuchi (1997) afirmam que a informação proporciona novo ponto de vista para a interpretação de eventos ou objetos, o que torna visível significados antes invisíveis. Assim, a informação como meio ou material para extrair e construir o conhecimento, acrescentando algo ou o reestruturando, constitui um fluxo de mensagens.

Desse modo, o conhecimento, como um conjunto de valores, informações de contexto, criatividade no trabalho e experiências acumuladas pelas pessoas, é criado por esse fluxo de informações, ancorado nas crenças e compromissos de seu detentor. Está essencialmente relacionado à ação humana, ou seja, é sempre conhecimento com algum fim. Ressalta-se que tanto o conhecimento como a informação, são específicos ao contexto e relacionais, na medida em que dependem da situação, sendo criados de forma dinâmica na interação social entre as pessoas. 
A criação de conhecimento organizacional pode ser entendida como um processo que amplia o conhecimento criado pelos indivíduos, cristalizando-os como parte da rede organizacional. Em se tratando de uma instituição hospitalar, para Bansal (2001) o seu maior ativo é formado pelo conjunto de conhecimentos dos médicos, paramédicos e outros profissionais não-médicos que têm contato com o cuidado dos pacientes. Inclui ainda os funcionários ligados ao ambiente operacional e tecnológico, que dão suporte à elaboração de rotinas médicas e administrativas. Sumariamente, a gestão do conhecimento em hospitais identifica e monitora ativos intelectuais, que geram conhecimentos capazes de assegurar alguma vantagem competitiva para a instituição.

Contudo, esse conhecimento só é criado pelos indivíduos, cabendo à organização proporcionar meios e contextos que possibilitem e tornem possível o aprimoramento do conhecimento. Em razão desses aspectos não formais para geração de conhecimento, Nonaka e Takeuchi (1997, p.7) propõem distingui-los em tácito e explícito:

“a) conhecimento tácito - é aquele não escrito em lugar algum, como as habilidades, percepções, insight, palpites, intuições e visão de mundo enraizada nas ações e nas experiências dos indivíduos. São componentes subjetivos, de difícil visualização e formalização, transmissão e compartilhamento; e

b) conhecimento explícito - é aquele registrado, expresso em palavras ou números. São componentes objetivos, disponíveis para todas as pessoas, podendo ser facilmente comunicado e compartilhado sob a forma de dados brutos como: fórmulas científicas, procedimentos codificados ou princípios universais”.

A gestão do conhecimento preconiza as sucessivas passagens do conhecimento tácito para explícito, e vice-versa, à medida que busca transformar o conhecimento individual em recursos disponíveis às outras pessoas, por meio da conversão do conhecimento tácito em palavras ou números possíveis de serem compreendidos. Assim, durante esse período de conversões, tem-se a disseminação e criação do conhecimento organizacional.

O conhecimento na organização representa o manancial natural de inteligência no ambiente empresarial, em que a equipe de trabalho é encarada de forma mais ampla, responsável, pensante, autônoma e com ações de caráter decisório no compartilhamento de conhecimento, processos, problemas e soluções. A capacidade em adquirir e desenvolver o conhecimento é inerente ao ser humano, e isto diferencia o recurso conhecimento dos demais.

No entanto, o conhecimento precisa ser gerenciado como os demais recursos 
para maximização, tornando-o um importante elemento na busca de um diferencial para a organização. Nessa perspectiva vêm surgindo, na literatura, metodologias de avaliação da gestão do conhecimento. A seguir, faz-se uma incursão teórica nas mais comumente contempladas na abordagem do tema.

\section{Metodologias de Avaliação da Gestão do Conhecimento}

A proposição de que a inteligência humana e os recursos intelectuais constituem os ativos mais valiosos e estratégicos das empresas tem sido amplamente focada por diversos autores, na tentativa de compreender sua importância para a evolução das organizações. Propor metodologias para avaliar o valor real das empresas requer a consideração dos ativos intangíveis. Contudo não há ferramentas unânimes que permitam traduzir objetivamente tal riqueza. Antunes (2000) enfatiza ser imprescindível aos gestores o conhecimento, a identificação e a mensuração desses ativos ocultos, para administrar sua continuidade e divulgar informações mais próximas da realidade.

Nesse sentido, Sveiby (1998) propõe que os ativos invisíveis, no balanço patrimonial de uma organização, sejam classificados em grupo de três elementos: (1) competência do funcionário; (2) estrutura interna; e (3) estrutura externa. Cada um desses grupos contempla indicadores de Crescimento e Renovação, Eficiência e Estabilidade. O Quadro 1 descreve os indicadores de avaliação para as três segmentações de ativos intangíveis.

\section{Quadro 1: Monitor de Ativos Intangíveis}

\begin{tabular}{|l|l|l|}
\hline \multicolumn{1}{|c|}{ Competência } & \multicolumn{1}{c|}{ Estrutura Interna } & \multicolumn{1}{c|}{ Estrutura Externa } \\
\hline $\begin{array}{l}\text { Indicadores de crescimento e } \\
\text { renovação }\end{array}$ & $\begin{array}{l}\text { Indicadores de crescimento e } \\
\text { renovação }\end{array}$ & $\begin{array}{l}\text { Indicadores de crescimento e } \\
\text { renovação }\end{array}$ \\
\hline Indicadores de eficiência & Indicadores de eficiência & Indicadores de eficiência \\
\hline Indicadores de estabilidade & Indicadores de estabilidade & Indicadores de estabilidade \\
\hline
\end{tabular}

Fonte: adaptado de Sveiby (1998, p.197).

O modelo recebe o nome de Monitor de Ativos Intangíveis. É utilizado pelos gerentes como indicador de medidas de avaliação para fins internos. O gestor deve selecionar apenas um ou dois indicadores para cada subtítulo do quadro, pois a utilização excessiva de índices pode confundir os leitores.

Quanto à finalidade da avaliação, Sveiby (1998) relaciona duas prioridades 
principais: (1) apresentação externa, em que a empresa descreve, da forma mais precisa possível, aos clientes, credores, acionistas e outros usuários, a qualidade de sua gerência e a possibilidade de poder tratar um fornecedor ou credor como confiáveis; e (2) avaliação interna, funcionando como um sistema de gerenciamento de informações que possibilita à gerência conhecer profundamente a empresa, monitorar seu progresso e tomar medidas corretivas. Não obstante, ele ressalta que o interessante é fazer comparações com alguns parâmetros estabelecidos, além do acompanhamento em diversos períodos consecutivos:

"uma avaliação nada significa se não for comparada a algum tipo de referencial: a uma outra empresa, ao ano anterior ou a um orçamento [...]. Ao avaliarmos ativos intangíveis, devemos, portanto, estar preparados para dar prosseguimento às avaliações de modo a cobrir, pelo menos, três ciclos de avaliação, antes de tentar avaliar os resultados. O ideal é que essas avaliações sejam repetidas anualmente” (Sveiby, 1998, p. 196).

Nenhum sistema de avaliação será útil para a tomada de decisões sem a possibilidade de comparar os mesmos indicadores com as empresas que operam em segmentos congêneres ou aos mesmos indicadores de períodos anteriores. A ênfase, por conseguinte, de todo o sistema de avaliação deve estar adaptada ao usuário final, de forma que o gerenciamento das informações internas busquem enfatizar o fluxo, a mudança e o controle. As apresentações externas devem incluir indicadores-chaves e um texto explicativo, porque não é possível compilar um balanço patrimonial inteiro que expresse todos os ativos intangíveis em termos monetários.

Outra abordagem, mas na mesma linha de raciocínio, proposta por Edvisson e Malone (1998), sugere que o método mais elementar para entender o capital intelectual é por meio da linguagem metafórica, comparando-se a empresa com uma árvore. Os autores consideram a parte visível o descrito em organogramas, relatórios anuais, demonstrativos financeiros e outros documentos; o que está abaixo da superfície terrestre é o capital intelectual, os fatores dinâmicos ocultos que embasam a empresa visível. Estes fatores dinâmicos ocultos são divididos em dois grupos: Capital Humano e Capital Estrutural.

O Capital Humano é composto por conhecimento, experiência, poder de inovação, habilidade dos empregados, cultura e filosofia da empresa, além da capacidade dos funcionários de combinar conhecimentos e habilidades para inovar suas funções, os quais não podem ser propriedades da empresa. O Capital Estrutural compreende os equipamentos de informática, softwares, bancos de dados, patentes, marcas registradas e o restante da capacidade organizacional que apóia a produtividade dos empregados e o relacionamento com os clientes, os quais são propriedades da empresa. 
Com referência ao relacionamento com os clientes, os autores crêem ser prudente desdobrá-lo para a categoria Capital de Clientes, pois denota maior importância da empresa. Desse modo, o Capital de Clientes contempla o valor do relacionamento com os clientes, que, embora soe estranho, sempre esteve presente de forma oculta no goodwill, obtido mediante a subtração do valor de mercado da empresa, quando negociada por um valor superior ao contábil, com o valor das patentes e os direitos autorais.

Juntas essas novas formas de avaliação do capital, para Edvinsson e Malone (1998), captam uma empresa em movimento, à medida que transformam suas habilidades e seus conhecimentos em competitividade e riqueza. Por conseguinte, os autores, como pioneiros na formalização de instrumentos para avaliação do capital intelectual, aplicaram sua metodologia na companhia sueca de seguros e serviços financeiros Skandia, denominando o instrumento proposto de Navegador Skandia, o qual utiliza indicadores para cinco áreas distintas de focos, representadas na Figura 1.

\section{Figura 1: Navegador Skandia}

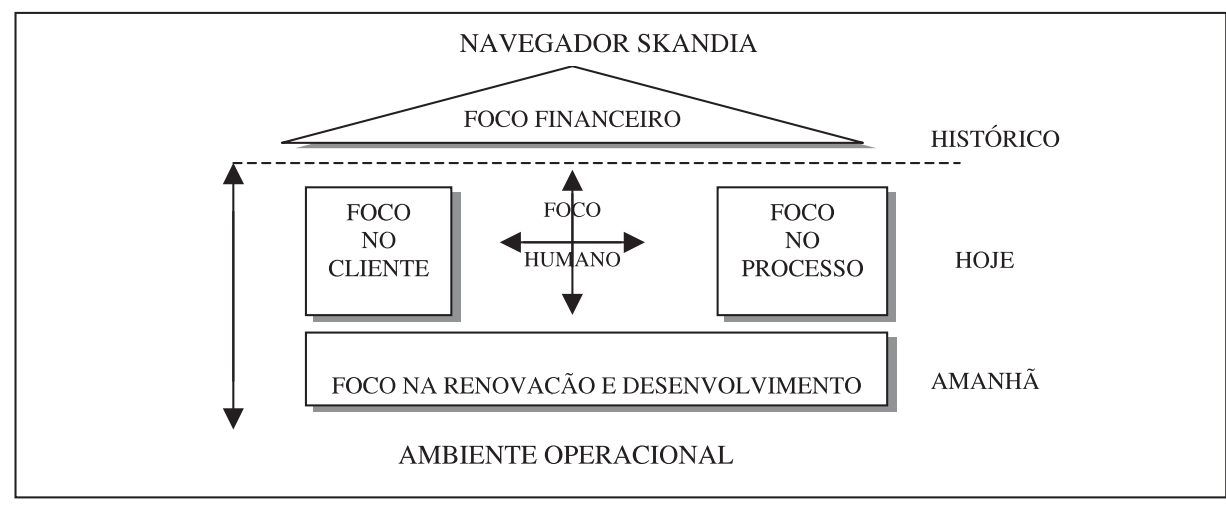

Fonte: Edvinsson e Malone (1998, p.60).

Dentro de cada foco foram estabelecidos indicadores que permitem avaliar o desempenho, sendo que a combinação dos cinco focos acaba em relatórios diferentes e dinâmicos. Os focos utilizados na representação do Navegador são áreas nas quais uma empresa direciona sua atenção. Desses focos origina-se o valor do capital intelectual no âmbito de seu ambiente.

Por fim, como uma outra forma de avaliar o capital intelectual, Stewart (1998) segmenta sua metodologia em quatro grupos: (1) medidas do todo; (2) medidas do capital humano; (3) medidas do capital estrutural; e (4) medidas do capital de clientes, recebendo o nome de Navegador do Capital Intelectual. Vale ressaltar que suas aplicações resultam em uma alternativa para visualizar, de forma 
simultânea, diversas dimensões do capital intelectual e que poderiam atuar como um facilitador na gerência dos ativos do conhecimento.

A Figura 2 ilustra o navegador do capital intelectual proposto por Stewart (1998) à uma empresa fictícia, utilizando uma medida geral denominada de Razão Valor de Mercado/Valor Contábil, e três indicadores para cada um dos itens do capital humano, estrutural e do cliente.

\section{Figura 2: Navegador do Capital Intelectual}

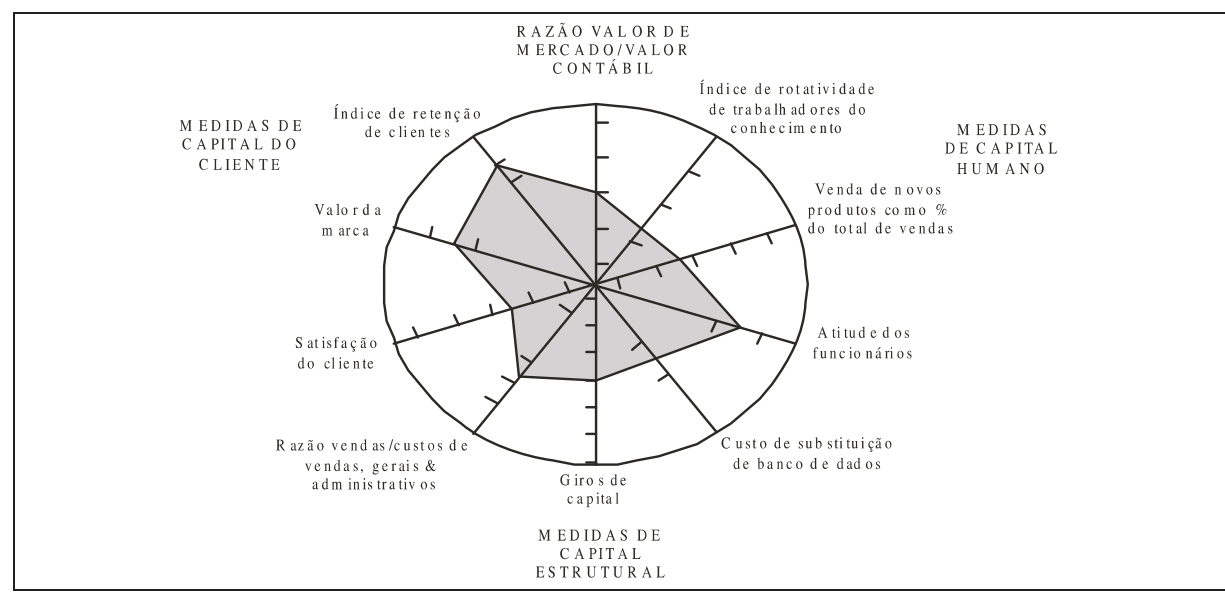

Fonte: Stewart (1997, p. 219).

O navegador apresenta escalas nos eixos sem se preocupar em demonstrar valores. Caso se referisse a uma empresa real, definiriam as escalas de maneira que as metas fossem alocadas às extremidades, onde o eixo cruza o círculo. Traçando a posição em cada escala e ligando os pontos, obtém-se um polígono, mostrando no interior os resultados atuais e na parte externa o que se deseja.

Com base nas três metodologias evidenciadas e consideradas as particularidades de uma organização hospitalar, enquadrada como filantrópica, elaborou-se uma proposta de metodologia de avaliação da gestão do conhecimento.

Metodologia de Avaliação da Gestão do Conhecimento para uma Entidade Filantrópica Voltada para a Área de Saúde

A metodologia de avaliação que se propõe para os ativos intangíveis não 
objetiva contemplar um quadro completo de medidas e indicadores pesquisados, que poderiam ser aplicáveis ao segmento hospitalar, pois um sistema de avaliação com essa amplitude parece ser impossível estratégica, metodológica e financeiramente, no momento. Busca-se uma linguagem diferente, usada para elaborar um relatório dinâmico, destinado ao público que ultrapassa as fronteiras da diretoria, cuja finalidade é proporcionar alguns indicadores para que os gestores de entidades filantrópicas voltadas para a área de saúde, particularmente uma organização hospitalar, possam começar a avaliar sua organização.

Nessa perspectiva, qualquer instrumento de avaliação é limitado pelo princípio da incerteza: todos dependem do observador. Portanto em face da real impossibilidade de se elaborar um modelo de divulgação e avaliação da gestão do conhecimento verdadeiramente universal, que abarque todas as organizações, a metodologia proposta, preferencialmente, deve servir como um referencial a partir da qual se possa trabalhar para criar um formato que melhor convenha a cada instituição.

A proposta é denominada de Monitor da Gestão do Conhecimento, fruto da reflexão teórica e comparação dos modelos apresentados por Stewart (1997), Edvinsson e Malone (1998) e Sveiby (1998). O Monitor da Gestão do Conhecimento é composto por três capitais: capital humano; capital estrutural; e capital de clientes. Esses devem ser monitorados e gerenciados para a efetiva administração da organização que atua no segmento hospitalar.

O capital humano refere-se à competência dos profissionais, do pessoal de suporte e dos autônomos contratados no setor de saúde. Entende-se por profissionais todas as pessoas que produzem, planejam, processam e apresentam produtos ou soluções, as quais estão diretamente envolvidas no trabalho com o cliente, como, por exemplo, os médicos, psicólogos, assistentes sociais, dentistas, terapeutas ocupacionais, enfermeiros, farmacêuticos e nutricionistas. O pessoal de suporte compreende os funcionários que trabalham nos setores de contabilidade, controladoria, financeiro, administração, higiene e saneamento, nutrição e dietética, motoristas e outros, e que contribuem de forma direta com a estrutura interna. Os autônomos contratados englobam os especialistas externos envolvidos na instituição, como os médicos plantonistas temporários, advogados, consultores, auditores independentes.

De forma genérica, o capital humano é composto por toda capacidade, habilidade e experiência individual dos profissionais, pessoal de suporte e autônomos contratados, cujo principal objetivo é o atendimento aos clientes e a melhoria da prestação dos serviços. O capital humano envolve o conhecimento 
tácito - pessoal, específico ao contexto e, assim, difícil de ser formulado e compartilhado.

Com relação ao capital estrutural, representa o fluxo de conhecimento dentro da organização. Pode ser definido como o conjunto de sistemas administrativos, conceitos organizacionais, modelos, rotinas, marcas, imagens da empresa, patentes, softwares, invenções, banco de dados, publicações, enfim, toda a infra-estrutura necessária para fazer uma empresa funcionar. O capital estrutural servindo de suporte ao capital humano é o único dos capitais do Monitor da Gestão do Conhecimento que pertence à organização como um todo. Por isso, seu valor pode ser calculado com maior precisão.

O capital de clientes inclui marcas e imagens, além de representar o fluxo externo de conhecimento nas relações com os clientes. É o valor do relacionamento com os clientes. A Figura 3 elucida o grupo de indicadores para os capitais da gestão do conhecimento, que se acredita ser aplicável a uma instituição hospitalar.

\section{Figura 3: Indicadores para os Capitais da Gestão do Conhecimento}

\begin{tabular}{|c|c|c|}
\hline CAPITAL HUMANO & CAPITAL ESTRUTURAL & CAPITAL DE CLIENTE \\
\hline $\begin{array}{l}\text { Indicadores de } \\
\text { crescimento e renovação }\end{array}$ & $\begin{array}{l}\text { Indicadores de crescimento } \\
\text { e renovação }\end{array}$ & $\begin{array}{l}\text { Indicadores de crescimento } \\
\text { e renovação }\end{array}$ \\
\hline Indicadores de eficiência & Indicadores de eficiência & Indicadores de eficiência \\
\hline Indicadores de estabilidade & Indicadores de estabilidade & Indicadores de estabilidade \\
\hline
\end{tabular}

Os indicadores para a avaliação e gerenciamento do capital humano buscam conhecer os requisitos essenciais para a contratação de funcionários; os investimentos destinados à qualificação profissional por meio de treinamentos e cursos; a motivação para execução melhorada de suas atribuições; e as recompensas pela dedicação à empresa. Objetivamente, avaliam a satisfação e retenção dos funcionários.

Nesse sentido, os indicadores de crescimento e renovação propõem verificar: tempo de profissão, nível de escolaridade, custo de treinamento e educação per capita, rotatividade da competência, tempo de treinamento no ano. Já os indicadores para verificação da eficiência do capital humano propõem acompanhar: proporção de profissionais na empresa e as habilidades dos funcionários valorizadas pelos clientes. Por fim, os indicadores para mensuração da estabilidade do capital humano buscam analisar: média etária, tempo de serviço e taxa de rotatividade de funcionários. 
Tais indicadores possibilitam um avanço no processo de se avaliar o capital humano da organização sob a ótica do crescimento e renovação, eficiência e estabilidade. Segundo Edvinsson e Malone (1998), uma empresa sem a dimensão do fator humano bem sucedido, fará com que as demais atividades de criação de valor não dêem certo, independentemente do nível de sofisticação tecnológica.

Com referência ao capital estrutural, acredita-se ser possível analisar o crescimento e a renovação a partir das verificações: investimento na estrutura interna, investimentos em sistemas de processamento de informações, sugestões feitas versus sugestões implementadas. No que concerne aos indicadores para verificar a eficiência do capital estrutural, sugere-se: proporção de pessoal de suporte, pacientes atendidos por pessoal de suporte e conhecimento dos funcionários em informática. Para acompanhar a estabilidade do capital estrutural, sugere-se os seguintes indicadores: idade da organização, rotatividade do pessoal de suporte e taxa de novatos.

Os indicadores para o crescimento e renovação do capital de cliente fornecem os seguintes parâmetros: número de clientes e superávit por cliente. A eficiência do capital de clientes pode ser avaliada por meio da aplicação dos seguintes indicadores: índice de clientes satisfeitos e receita anual por clientes. Por fim, os indicadores para mensuração da estabilidade do capital de cliente buscam analisar: estrutura etária e freqüência de retornos para continuação do tratamento.

A maior parte dos indicadores listados para a mensuração do capital de cliente está baseada em fluxos de conhecimento, em substituição às medidas financeiras usadas nos demais indicadores. Podem ser adotados, principalmente, para fins de tomada de decisões estratégicas pelos diretores de empresas hospitalares. Uma vez abordada a proposta de avaliação a gestão do conhecimento, a etapa seguinte consiste na sua aplicação em uma organização hospitalar.

\section{Aplicação da Proposta em uma Organização Hospitalar FILANTRÓPICA}

Inicialmente, faz-se uma breve apresentação da organização hospitalar que serviu de suporte para aplicação do monitor para avaliação da gestão do conhecimento. Na seqüência, apresenta-se o modelo do monitor da gestão do conhecimento, com os respectivos indicadores do capital humano, capital estrutural e capital de cliente. 
Constituída em 1978, cuja denominação não se declina por razões diversas, é uma entidade filantrópica, especializada no tratamento psiquiátrico e de alcoolismo. Possui $10.000 \mathrm{~m}^{2}$ de área construída, 140 funcionários nas áreas de medicina psiquiátrica, medicina clínica, odontologia, psicologia, terapia ocupacional, farmacologia, administração, higiene e saneamento, nutrição e dietética e manutenção do patrimônio físico. Mantida exclusivamente com recursos provenientes do Sistema Único de Saúde (SUS), possui capacidade para atendimento a 300 pacientes por dia em regime de internamento, além de servir de hospital-escola para várias universidades circunvizinhas.

Para ilustrar o monitor da gestão do conhecimento da organização hospitalar, apresenta-se sua aplicação, conforme evidenciado no Quadro 2, a qual contempla a avaliação do desempenho dos ativos intangíveis com base nos dados fornecidos pela instituição referentes ao ano de 2001.

O monitor da gestão do conhecimento configura-se com um formato de apresentação dos indicadores relevantes que auxiliam na mensuração do capital intangível das empresas hospitalares. Ressalta-se que a existência de várias medidas não-financeiras possíveis de serem adaptadas ao monitor proposto, pode levar a organização a utilizar um número excessivo de índices, superlotando e confundindo os instrumentos gerenciais.

Cabe às organizações selecionarem os que mais lhes convenham para cada um dos subtítulos do monitor e acompanhá-los periodicamente. Assim, a escolha dos indicadores depende da estratégia da organização, os quais podem ser utilizados, sobretudo, para o acompanhamento de uma estratégia orientada para o conhecimento.

Por fim, recomenda-se integrar o monitor da gestão do conhecimento ao sistema de gerenciamento de informações das organizações hospitalares, complementandoos com relatórios analíticos para facilitar o entendimento e esclarecer os aspectos subjetivos. 


\section{Quadro 2: Monitor da Gestão do Conhecimento}

\begin{tabular}{|c|c|c|c|c|c|}
\hline \multicolumn{2}{|l|}{$\begin{array}{l}\text { CAPITAL } \\
\text { HUMANO }\end{array}$} & \multicolumn{2}{|l|}{$\begin{array}{c}\text { CAPITAL } \\
\text { ESTRUTURAL }\end{array}$} & \multicolumn{2}{|c|}{$\begin{array}{c}\text { CAPITAL } \\
\text { DE CLIENTE }\end{array}$} \\
\hline \multicolumn{2}{|c|}{ Crescimento e Renovação } & \multicolumn{2}{|l|}{ Crescimento e Renovação } & \multicolumn{2}{|c|}{ Crescimento e Renovação } \\
\hline Tempo de profissão & 16 anos & $\begin{array}{l}\text { Investimento na estrutura } \\
\text { Interna (8) }\end{array}$ & $0,20 \%$ & \begin{tabular}{|l|} 
Número de clientes \\
$(12)$
\end{tabular} & 9360 \\
\hline Nível de escolaridade (1) & $\begin{array}{l}\text { (1) } 23 \% \\
\text { (2) } 45 \% \\
\text { (3) } 23 \%\end{array}$ & $\begin{array}{l}\text { Investimento em sistema de } \\
\text { processamento de } \\
\text { informações (9) }\end{array}$ & $0,50 \%$ & Superávit por cliente & $\mathrm{R} \$ 7,47$ \\
\hline $\begin{array}{l}\text { Custo de treinamento e } \\
\text { Educação per capita }\end{array}$ & 8,57 & $\begin{array}{l}\text { Sugestões feitas versus } \\
\text { sugestões implementadas (10) }\end{array}$ & $87 \%$ & & \\
\hline $\begin{array}{l}\text { Rotatividade da } \\
\text { competência (2) }\end{array}$ & $15,6 \%$ & & & & \\
\hline $\begin{array}{l}\text { Tempo de treinamento } \\
\text { no ano (3) }\end{array}$ & 25 dias & & & & \\
\hline \multicolumn{2}{|l|}{ Eficiência } & \multicolumn{2}{|l|}{ Eficiência } & \multicolumn{2}{|l|}{ Eficiência } \\
\hline $\begin{array}{l}\text { Proporção de profissionais } \\
\text { na empresa (4) }\end{array}$ & $67 \%$ & $\begin{array}{l}\text { Proporção de pessoal de } \\
\text { suporte }\end{array}$ & $33 \%$ & $\begin{array}{l}\text { Índice de clientes } \\
\text { satisfeitos (13) }\end{array}$ & $86 \%$ \\
\hline $\begin{array}{l}\text { Habilidades dos } \\
\text { funcionários valorizadas } \\
\text { pelos clientes (5) }\end{array}$ & $\begin{array}{l}\text { (1) } 42 \% \\
\text { (2) } 22 \% \\
\text { (3) } 36 \%\end{array}$ & $\begin{array}{l}\text { Pacientes atendidos por } \\
\text { pessoal de suporte }\end{array}$ & 203 & $\begin{array}{l}\text { Receita anual por } \\
\text { cliente }\end{array}$ & $\begin{array}{c}\mathrm{R} \$ \\
256,41\end{array}$ \\
\hline & & $\begin{array}{l}\text { Conhecimento dos } \\
\text { funcionários em informática }\end{array}$ & $9,33 \%$ & & \\
\hline \multicolumn{2}{|l|}{ Estabilidade } & \multicolumn{2}{|l|}{ Estabilidade } & Estabilidade & \\
\hline Media etária (6) & 34 anos & Idade da organização & $\begin{array}{l}23 \\
\text { anos }\end{array}$ & Estrutura etária (14) & 12 anos \\
\hline Tempo de serviço (7) & 8 anos & $\begin{array}{l}\text { Rotatividade do pessoal de } \\
\text { suporte (11) }\end{array}$ & $6,52 \%$ & $\begin{array}{l}\text { Frequiência de } \\
\text { retornos para } \\
\text { continuidade do } \\
\text { tratamento }(15) \\
\end{array}$ & $83 \%$ \\
\hline $\begin{array}{l}\text { Taxa de rotatividade } \\
\text { de funcionários }\end{array}$ & $8,57 \%$ & Taxa de novatos & $7,85 \%$ & & \\
\hline
\end{tabular}

Notas:

(1) O nível de escolaridade refere-se: (1) primeiro grau, (2) segundo grau e (3) terceiro grau.

(2) Rotatividade da competência: está relacionada ao percentual de substituição dos profissionais do hospital.

(3) Tempo de treinamento: médias de dias anual que os funcionários dedicaram a aperfeiçoamento profissional.

(4) Proporção de profissionais na empresa: obtido em relação ao total de funcionários do hospital.

(5) Habilidades dos funcionários valorizadas pelos clientes: analisado a partir de uma pesquisa direcionada, questionado-se (1) agilidade nas ocorrências com pacientes, (2) conhecimento das normas do hospital, (3) cordialidade e paciência trato com os clientes.

(6) Média etária: idade média dos funcionários.

(7) Tempo de serviço: número de anos de dedicação a empresa.

(8) Investimento na estrutural interna: percentual da receita total destinado a novas métodos ou sistemas, banco de dados, manuais, padrões de qualidade, propagandas, design.

(9) Investimento em sistema de processamento de informações: percentual sobre a receita total.

(10) Sugestões feitas versus sugestões implementadas: proporção de sugestões dos funcionários e clientes implantadas.

(11) Rotatividade do pessoal de suporte: proporção de substituição em relação ao total de funcionários.

(12) Número de clientes: refere-se ao número de clientes atendidos no ano - internamento e consultas.

(13) Número de clientes satisfeitos: apurado por meio de pesquisa direcionada a família e ao cliente/ paciente.

(14) Estrutura etária: indica a média de anos que o cliente freqüenta o hospital para consultas e internamentos.

(15) Freqüência de retornos para continuidade do tratamento: com base no número total de clientes. 


\section{Considerações Finais}

A gestão do conhecimento está vinculada à administração, utilização, criação e disseminação da informação para atingir os objetivos da organização, isto é, está imbricada nos processos de aprendizagem organizacional. Dessa forma, a essência da gestão do conhecimento se encontra em torno das sucessivas transposições de conhecimentos tácitos a uma forma explícita, o que, via de regra, depende exclusivamente do interesse das pessoas que os detém, e se prontificarem a repassar esse conhecimento às demais pessoas.

Têm-se como conceitualmente aceito, que o conhecimento humano tornou-se um recurso econômico proeminente e estratégico na era da informação, dado a agregação de valor às empresas. Portanto, consta como o bem mais valioso e poderoso, até mesmo superior aos próprios recursos naturais ou todos os bens físicos que as organizações possuem registrados em seus ativos.

Dadas as particularidades dos ativos intangíveis, caracterizam-se como investimentos de difícil avaliação, constituindo-se um desafio atribuir-lhes valores monetários. Os indicadores apresentados pelos autores pesquisados são essencialmente não-financeiros e alicerçados nos conceitos de organizações do conhecimento. A falta de uma estrutura teórica coerente aos setores emergentes é uma característica da atualidade. Assim a maior dificuldade não reside em criar-se medidas intangíveis, mas, aparentemente, em interpretá-las. Os indicadores, de maneira geral, tentam identificar como as ações empregadas nas empresas influenciam o valor dos ativos, uma vez que o valor de mercado de uma empresa é constituído tanto pelo patrimônio visível, quanto por seus ativos intangíveis. Em uma organização filantrópica hospitalar os indicadores avaliam as ações implementadas pela gestão quanto à capacitação das pessoas e à adequação do ambiente físico que melhor dão suporte ao atendimento médico aos clientes.

A partir da proposta de avaliação da gestão do conhecimento elaborada, acreditase ser possível acompanhar o capital humano, o capital estrutural e o capital de clientes, sob a ótica do crescimento e renovação, eficiência e estabilidade. Embora a proposta não contemple todos os indicadores possíveis para se avaliar os ativos intangíveis de uma entidade filantrópica, pois um sistema desse porte parece ser exaustivo e comprometedor da relação custo-benefício da informação, apresenta sugestões, a partir das quais podem-se criar indicadores de acordo com as necessidades e possibilidades de acompanhamento e comparações ao longo do tempo em cada organização hospitalar. 
Acredita-se que à medida que as pessoas interagem em seus ambientes, elas absorvem informações, as transformam em conhecimento e agem com base nessa combinação de conhecimentos, experiências, valores e regras internas, buscando identificar as informações como instrumento decisivo para alavancar o sucesso organizacional e criar diferenciais competitivos que sustentem sua permanência no mercado. Com o monitoramento das ações e estratégias, podese agregar maior valor à estrutura interna da organização hospitalar e, conseqüentemente, aos clientes, que cada vez mais desejam excelência no atendimento médico.

\section{Referências Bibliográficas}

AKSELRAD, M.

Tratamento tributário das instituições sem finalidades lucrativas. In: INTERNATIONAL FISCAL ASSOCIATION, 53., 2000, Israel. Anais Eletrônicos... Disponível em: <http://www.akselrad.adv.br/ ongs.htm> Acesso em: 20 abr. 2002.

ANTUNES, M. T. P.

Capital intelectual. São Paulo: Atlas, 2000.

BANSAL, M.

Knowledge management: capitalizing a hospital's assets. Express Healthcare Management. India's first newspaper for the health care business. Disponível em: <http:// www.expresshealthcaremgmt.com/ 20010915/editorial2.htm> Acesso em: 18 jul. 2003.
BEULKE, R.;

BERTÓ, D. J.

Gestão de custos e resultado na saúde. 2. ed. São Paulo: Saraiva, 2000.

\section{BRASIL.}

Lei das Oscips, Lei $\mathrm{n}^{\circ}$ 9.790, de 23 de março de 1999. Dispõe sobre a qualificação de pessoas jurídicas de direito privado, sem fins lucrativos, como Organizações da Sociedade Civil de Interesse Público, institui e disciplina o Termo de Parceria. [S.I.], 1999.

CAMPOS, J. de Q.

O hospital no contexto empresarial. São Paulo: Pioneira, 1987.

EDVINSSON, L.;

MALONE, M. S.

Capital intelectual: descobrindo o valor real de sua empresa pela identificação de seus valores internos. São Paulo: Makron Books, 1998. 
FALCONER, A. P.

A promessa do terceiro setor. Centro de Estudos em Administração do Terceiro Setor da Universidade de São Paulo, 2002. Disponível em: <http:// www.icd.org.uy/mercosur/ informes/2000/falconer4.html> Acesso em: 8 jun. 2003.

FLEURY, A.;

FLEURY, M. T. L.

Estratégias empresariais e formação de competências: um quebra-cabeça caleidoscópio indústria brasileira. São Paulo: Atlas, 2000.

GONÇALVES, E. L.

Administração de recursos humanos nas instituições de saúde. São Paulo: Pioneira, 1987.

GARVIN, D. A.

Construção da organização que aprende. In: Gestão do conhecimento. Rio de Janeiro: Campus, 2000.

JEREMIAS, C.;

BEUREN, I. M.

Contabilização dos recursos econômico-financeiros em entidades sem fins lucrativos não governamentais. In: CONGRESSO DE BRASILEIRO DE CUSTOS, XVI., 2000, Goiânia. Anais... Goiânia: ABC, 2000. 1 CD-ROM.
KOTLER, P.

Administração de marketing. 5. ed. São Paulo: Atlas, 1998.

MARINHO, A.

Estudo de eficiência em alguns hospitais públicos e privados com a geração de ranking. Revista de Administração Pública, 1998. Disponível em: <http:// www.ipea.gov.br> Acesso em: 10 jul. 2003.

NONAKA, I.;

TAKEUCHI, $\mathrm{H}$.

Criação de conhecimento na empresa: como as empresas japonesas geram a dinâmica da inovação. 6. ed. Rio de Janeiro: Campus, 1997.

PACHECO, V.

O capital intelectual e sua divulgação pela contabilidade de recursos humanos. Revista do Conselho Regional de Contabilidade do Paraná, n. 129, p. 31-37, jan./abr. 2001.

SENGE, $\mathrm{P}$.

As cinco disciplinas. HSM Management, v. 4, n. 9, p. 8288, jul./ago. 1998.

Além da quinta disciplina. HSM Management, v. 4, n. 19, mar./ abr. 2000. Disponível em: <www.intermanagers.com.br> Acesso em: 10 jul. 2001. 
SERAFIM FILHO, P.

A gestão do conhecimento e a motivação nas organizações. Revista Decidir, jan. 1999. Disponível em: <http:// www.perspectivas.com.br $>$ Acesso em: 29 abr. 2001.

STEWART, T. A.

Capital intelectual: a nova vantagem competitiva das empresas. 7. ed. Rio Janeiro: Campus, 1998.

SVEIBY, K. E.
$A$ nova riqueza das

organizações: gerenciando e avaliando patrimônios do conhecimento. 4. ed. Rio de Janeiro: Campus, 1998.

TEIXEIRA FILHO, J.

Gerenciando conhecimento. Rio de Janeiro: Senac, 2000.

\section{ZUCCHI, P.}

Funcionários por leito: estudo em alguns hospitais públicos e privados. Revista de Administração Pública, v. 32, n. 3, p. 65-76, maio/jun. 1998. 